\title{
Article \\ Prolonged Infusion of $\beta$-Lactams Decreases Mortality in Patients with Septic Shock: A Retrospective before-and-after Study
}

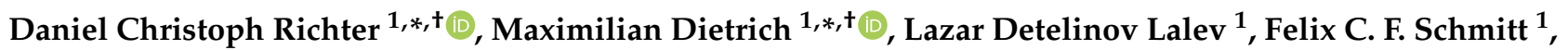 \\ Mascha Onida Fiedler ${ }^{1}{ }^{(D}$, Thomas Bruckner ${ }^{2}$, Dominic Stoerzinger ${ }^{3}$, Ute Chiriac ${ }^{3}{ }^{\mathbb{D}}$, Sabrina Klein ${ }^{4}$, \\ Thilo Hackert ${ }^{5}$, Thorsten Brenner ${ }^{6}$, Alexander Brinkmann ${ }^{7}$ and Markus A. Weigand ${ }^{1}$
}

check for updates

Citation: Richter, D.C.; Dietrich, M.; Lalev, L.D.; Schmitt, F.C.F.; Fiedler, M.O.; Bruckner, T.; Stoerzinger, D.; Chiriac, U.; Klein, S.; Hackert, T.; et al. Prolonged Infusion of $\beta$-Lactams Decreases Mortality in Patients with Septic Shock: A Retrospective before-and-after Study. Antibiotics 2021, 10, 687. https://doi.org/ 10.3390/antibiotics10060687

Academic Editor: Filippo Mariano

Received: 26 May 2021

Accepted: 7 June 2021

Published: 8 June 2021

Publisher's Note: MDPI stays neutral with regard to jurisdictional claims in published maps and institutional affiliations.

Copyright: (c) 2021 by the authors. Licensee MDPI, Basel, Switzerland. This article is an open access article distributed under the terms and conditions of the Creative Commons Attribution (CC BY) license (https:// creativecommons.org/licenses/by/ $4.0 /)$.
1 Department of Anesthesiology, Heidelberg University Hospital, Im Neuenheimer Feld 420, 69120 Heidelberg, Germany; lazardetelinov.lalev@med.uni-heidelberg.de (L.D.L.); felix.schmitt@med.uni-heidelberg.de (F.C.F.S.); mascha.fiedler@med.uni-heidelberg.de (M.O.F.); markus.weigand@med.uni-heidelberg.de (M.A.W.)

2 Institute of Medical Biometry \& Biostatistics, Im Neuenheimer Feld 130.3, 69120 Heidelberg, Germany; bruckner@imbi.uni-heidelberg.de

3 Department of Pharmacy, Heidelberg University Hospital, Im Neuenheimer Feld 670, 69120 Heidelberg, Germany; dominic.stoerzinger@med.uni-heidelberg.de (D.S.); ute.chiriac@med.uni-heidelberg.de (U.C.)

4 Department of Infectious Diseases, Medical Microbiology and Hygiene, Im Neuenheimer Feld 324, 69120 Heidelberg, Germany; sabrina.klein@med.uni-heidelberg.de

5 Department of General, Visceral and Transplantation Surgery, Heidelberg University Hospital, Im Neuenheimer Feld 420, 69120 Heidelberg, Germany; thilo.hackert@med.uni-heidelberg.de

6 Department of Anesthesiology and Intensive Care Medicine, University Hospital Essen, University Duisburg-Essen, Hufelandstraße 55, 45147 Essen, Germany; thorsten.brenner@uk-essen.de

7 Department of Anesthesiology, Heidenheim Hospital, Schloßhaustraße 100, 89522 Heidenheim, Germany; alexander.brinkmann@kliniken-heidenheim.de

* Correspondence: daniel.richter@med.uni-heidelberg.de (D.C.R.); maximilian.dietrich@med.uni-heidelberg.de (M.D.)

+ These authors contributed equally to this work.

\begin{abstract}
Septic shock substantially alters the pharmacokinetic properties of $\beta$-lactams with a subsequently high risk of insufficiently low serum concentrations and treatment failure. Considering their pharmacokinetic (PK)/pharmacodynamic (PD) index, prolonged infusions (PI) of $\beta$-lactams extend the time that the unbound fraction of the drug remains above the minimal inhibitory concentration MIC $(f \mathrm{t}>\mathrm{MIC})$ and may improve patient survival. The present study is a monocentric, retrospective before-and-after analysis of septic shock patients treated with $\beta$-lactams. Patients of the years 2015-2017 received intermittent bolus application whereas patients of 2017-2020 received PI of $\beta$-lactams. The primary outcome was mortality at day 30 and 90 after diagnosis of septic shock. Mortality rates in the PI group were significantly lower on day 30 (PI: $41 \%, n=119 / 290$ vs. IB: $54.8 \%$, $n=68 / 114 ; p=0.0097$ ) and day 90 (PI: $47.9 \%, n=139 / 290$ vs. IB: $62.9 \%, n=78 / 124 ; p=0.005$ ). After propensity-score matching, 30- and 90-day mortality remained lower for the PI group ( $-10 \%$, $p=0.14)$. PI was further associated with a reduction in the duration of invasive ventilation and a stronger decrease in SOFA scores within a 14 day-observation period. PI of $\beta$-lactams was associated with a significant reduction of mortality in patients with septic shock and may have beneficial effects on invasive ventilation and recovery from sepsis-related organ failure.
\end{abstract}

Keywords: prolonged infusion; $\beta$-lactams; septic shock; mortality; antibiotic therapy; critical care

\section{Introduction}

Sepsis has emerged as one of the most challenging global health problems, with increasing patient numbers (49 million cases) and persistently high mortality rates (11 million) [1,2]. The German INSEP study [3] included 1503 patients with sepsis and septic 
shock and found an overall intensive care unit (ICU) mortality of 34.3\% (compared with $6 \%$ in patients without sepsis) and a $40.4 \%$ hospital mortality of septic patients.

Rapid administration of broad-spectrum antibiotics is regarded a key feature of sepsis treatment [4]. Prospective studies found a 2 to $8 \%$ increase in mortality with each hour of antibiotic delay $[5,6]$. $\beta$-lactams like piperacillin/tazobactam (TZB) and carbapenems (CP) are considered frontline broad-spectrum antibiotics and are the most frequently prescribed substances for the treatment of sepsis and septic shock $[7,8]$. Sepsis and septic shock induce pathophysiological changes that gravely alter the pharmacokinetic properties of the hydrophilic $\beta$-lactams [9-11] and ultimately may culminate in low $\beta$-lactam serum concentrations [12-15] jeopardizing treatment success [16,17]. To provide critically ill patients with effective antimicrobial therapy, guidelines strongly support efforts to optimize antimicrobial dosing $[4,18,19]$. As time-dependent antibiotics, antimicrobial potency of $\beta$-lactams is predominantly determined by the time $(T)$ that the unbound fraction $(f)$ of the drug remains above the pathogen-specific minimal inhibitory concentration (MIC) [20,21]. However, in most immediate clinical scenarios, causative pathogens, MIC and measured serum concentrations of $\beta$-lactams are not readily available for treating physicians. In this case, pragmatic PK-targets considering epidemiological cut-off values (ECOFF) have been proposed (50-100\% $\mathrm{f}_{>2-4 \mathrm{MIC}}$ of possible resistant targets, like Pseudomonas aeruginosa) to ensure the best possible antimicrobial exposure. The prospective DALI study by Roberts et al. [22] investigated antimicrobial exposure in a cohort of critically ill patients treated with standard doses of eight distinct $\beta$-lactams (including $\mathrm{CP}$ and TZB). $67 \%$ of patients were treated with intermittent bolus (IB) application while 33\% received a prolonged infusion (PI). The investigators found acceptable PK-target attainment for the most conservative targets (Meropenem, 50\% $f \mathrm{~T}_{>\mathrm{MIC}}$ : $95 \%$; TZB, $50 \% f \mathrm{~T}_{>\mathrm{MIC}}$ : $80.6 \%$ of patients) but poor target attainment for pragmatic PK-targets aimed for in sepsis and septic shock (100\% $f \mathrm{~T}_{>4 \mathrm{MIC}}: 41.6 \%$ [Meropenem] and 30.3\% [TZB]). Overall, $48.8 \%$ of patients achieved $50 \%$ $f \mathrm{~T}_{>4 \mathrm{MIC}}$ and only $35 \%$ attained a target of $100 \%_{\mathrm{f}} \mathrm{T}_{>4 \mathrm{MIC}}$. With regard to PK properties, PI are a promising compromise to IB. Applying an initial loading dose (LD) and infusing subsequent doses over a period of 2 to $4 \mathrm{~h}$ is a pragmatic way to effectively extend the $f \mathrm{~T}_{>\mathrm{MIC} / \mathrm{ECOFF}}$ throughout the dosing interval. In contrast to continuous infusion $(\mathrm{CI})$ of $\beta$-lactams, therapeutic drug monitoring (TDM) is not essentially required. Abdul-Aziz and co-workers performed a post-hoc analysis [23] of the DALI study [22] to investigate effects of PI on patient mortality and found significantly higher 30-day-survival rates for patients receiving PI for respiratory infections (PI 86.2\% [ $n=25 / 29]$ vs. IB 56.7\% [17/30]) and patients with a SOFA score $\geq 9$ (PI 73.3\% [ $n=11 / 15]$ vs. IB 35\% [7/20]; $p=0.035$ ). A recent meta-analysis by Rhodes et al. [24] that included 18 studies with 3401 patients treated with TZB concordantly reported a 1.77 -fold higher odds of clinical cure $(95 \% \mathrm{CI}$, 1.24-2.54) and a 1.22-fold higher odds of microbiological cure (95\% CI, 0.84-1.77) in patients receiving PI. Older data by Falagas and co-workers [25] also reported lower mortalities for PI. Although, studies on PI of $\beta$-lactams comprise a broad spectrum of critically ill patients with varying degrees of disease severity and different foci of infection. For example, Abdul-Aziz et al. [23] included patients with a median SOFA score of 5 (IQR3-8) and predominantly respiratory $(38.5 \%)$ and abdominal $(27.5 \%)$ infections. We introduced PI of $\beta$-lactams in the surgical intensive care unit (ICU) at Heidelberg University Hospital in 2017. As we treat a relatively homogenous and severely ill cohort of patients with abdominal sepsis, the present analysis aims to investigate the effects of PI of $\beta$-lactams on mortality in severely ill patients with mainly abdominal septic shock. We matched the PI cohort to a comparable cohort of the years 2015-2017 when $\beta$-lactams were administered as IB.

\section{Materials and Methods}

\subsection{Study Design}

The present study is a monocentric, retrospective before-and-after analysis of electronically collected clinical data of the interdisciplinary surgical ICU at Heidelberg University 
Hospital, Germany. The local Institutional Ethics Committee approved the study (reference number: S-586/2020). We included adult patients (age $>18$ years) that were treated with $\beta$-lactam antibiotics for septic shock (according to the revised SSC definition [4]) between March 2015 and July 2020. Two groups were compared: patients of the years 2015-2017 received IB application, whereas patients of 2017-2020 received PI of $\beta$-lactams.

\subsection{Antimicrobial Treatment, Clinical Scores, Laboratory Data}

Sepsis therapy was based on the recommendations of the SSC [4] and the German Sepsis Society (DSG) [26]. The local protocol for the prolonged $\beta$-lactam administration since April 2017 consisted of an initial LD (30-min bolus infusion) and PI of consecutive doses over a period of $3 \mathrm{~h}$ using a rate-controlled syringe pump. Before April $2017 \beta$ lactam antibiotics were administered as an intermittent bolus of a 20 -min infusion. The LD comprised of one standard dose administered as bolus infusion. Despite the LD, patients in both groups (IB \& PI) received standard doses of the respective $\beta$-lactams. Doses were corrected according to the manufacturers' recommendation (mostly for acute kidney injury/renal failure). We did not conduct therapeutic drug monitoring (TDM).

The patients' clinical and demographic data presented in this study were derived from the clinical documentation system. Vasopressor dependence and inotropic support were summarized and analyzed using the vasoactive-inotropic score (VIS) as proposed by Butts et al. [27]:

VIS = dopamine dose $(\mu \mathrm{g} / \mathrm{kg} / \mathrm{min})+$ dobutamine dose $(\mu \mathrm{g} / \mathrm{kg} / \mathrm{min})+100 \times$ epinephrine dose $(\mu \mathrm{g} / \mathrm{kg} / \mathrm{min})+100 \times$ norepinephrine dose $(\mu \mathrm{g} / \mathrm{kg} / \mathrm{min})+10,000 \times$ vasopressin dose $(\mathrm{U} / \mathrm{kg} / \mathrm{min})+10 \times$ milrinone dose $(\mu \mathrm{g} / \mathrm{kg} / \mathrm{min})$

Assessed laboratory data included leucocyte count, C-reactive protein (CRP), procalcitonin (PCT), creatinine, transaminases (aspartate and alanine aminotransferase), bilirubin and albumin levels. Sepsis-related organ failure assessment (SOFA) score [28] and acute physiology and chronic health evaluation II (APACHE 2) [29] scores were used to assess the degree of organ dysfunction/failure and as a surrogate for disease severity. Laboratory data, the amount of catecholamines administered were obtained at study inclusion, $48 \mathrm{~h}$, $96 \mathrm{~h}, 168 \mathrm{~h}$ and 14 days after study inclusion.

\subsection{Clinical Outcome Measures}

We analyzed differences in mortality rates of patients treated with IB and PI. The primary outcome was mortality at day 30 and 90 after recognition of septic shock. In addition, overall ICU- and hospital mortality was assessed. Secondary outcomes included the ICU length of stay and the duration of invasive ventilation. Vasopressor dependence (VIS), the serum CRP, PCT and SOFA score were evaluated at enrollment 48 h, 96 h, 7 days and 14 days after study inclusion.

\subsection{Statistical Methods}

Data was collected with the aid of an electronic database system (Microsoft Excel ${ }^{\circledR}$, Microsoft Deutschland GmbH, Unterschleißheim, Germany). The SAS System (Version 9.4, SAS, Cary, NC, USA) was used for statistical analyses. Descriptive statistics were done for the complete dataset. To adjust for baseline differences between the PI group and the IB group for the primary and secondary endpoint analysis, a propensity-score matching was performed including age, sex, SOFA- and vasoactive-inotropic score. For continuous variables and scores, mean, standard deviation (SD), minimum, median and maximum were calculated. Mean values with SD are presented in the manuscript. Absolute and relative frequencies of categorical variables are presented. The t-test test was used for the comparison of metric data between unpaired samples. For the comparison of categorical data, the chi-square test was used. Survival analysis was performed using a KaplanMeier graph with log-rank test and a fixed observation period of 30 days. Laboratory 
data and score courses over time were evaluated by analyses of covariance with repeated measurements. Appropriate statistical graphics were used to visualize the findings.

\section{Results}

\subsection{Baseline Characteristics}

A total of 414 septic shock patients were eligible for inclusion into the final statistical analysis. The cohorts differed in sample size (IB group $n=124$, PI group $n=290$ patients). Both groups did not significantly differ regarding demographical baseline data (Table 1). Mean SOFA scores of 13.5 (3.3) (IB) and 12.6 (2.9) (PI)—although significantly differenthowever, indicated an equal severity of disease in both groups. Renal impairment measured as mean GFR was moderate (GFR IB 56 [46] vs. PI 56 [40] mL/min) (Table 1). 43\% $(n=53 / 124)$ of patients in the IB group and $40 \%(n=116 / 290)$ needed at least temporal renal replacement therapy for sepsis related acute renal failure. Abdominal foci were most common in both groups (IB: $66 \%, n=82 / 124$ and PI $76 \%, n=221 / 290$ ). For the primary and secondary endpoints, additional propensity-score matched analyses were performed. Both matched groups included 112 patients. The Propensity-Score matched PI group had a lower rate of known tumor disease. SOFA score was lower, APACHE II score was higher in the propensity-score matched PI group than in the propensity-score matched IB group. The baseline characteristics of all patients and the propensity-score matched cohorts are given in Table 1. Figure 1A depicts the distribution of antibiotics utilized for treatment. The doses per day and bodyweight of the most commonly used antibiotics are presented in the following:
TZB:
PI group $0.2 \mathrm{~g} / \mathrm{kg} / \mathrm{d}(0.1)$
Meropenem:
PI group $0.05 \mathrm{~g} / \mathrm{kg} / \mathrm{d}(0.03)$
Imipenem:
PI group $0.04 \mathrm{~g} / \mathrm{kg} / \mathrm{d}(0.02)$
vs. IB group $0.19 \mathrm{~g} / \mathrm{kg} / \mathrm{d}(0.06)$
vs. IB group $0.04 \mathrm{~g} / \mathrm{kg} / \mathrm{d}(0.01)$
vs. IB group $0.04 \mathrm{~g} / \mathrm{kg} / \mathrm{d}(0.01)$

Table 1. Patient characteristics at study enrollment (onset of septic shock*) in baseline cohort and propensity-score analysis.

\begin{tabular}{|c|c|c|c|c|c|c|}
\hline \multicolumn{4}{|c|}{ Baseline $(n=414)$} & \multicolumn{3}{|c|}{ Propensity-Score Matched $(n=224)$} \\
\hline \multicolumn{2}{|c|}{$\begin{array}{l}\text { Intermittent Bolus } \\
\quad(n=124)\end{array}$} & $\begin{array}{l}\text { Prolonged Infusion } \\
\quad(n=290)\end{array}$ & $p$-Value & \multirow{2}{*}{$\begin{array}{l}\text { Intermittent Bolus } \\
\quad(n=112)\end{array}$} & \multirow[t]{2}{*}{$\begin{array}{l}\text { Prolonged Infusion } \\
\quad(n=112)\end{array}$} & \multirow[t]{2}{*}{$p$-Value } \\
\hline \multicolumn{4}{|c|}{ Demographic data } & & & \\
\hline Male sex & $86(69 \%)$ & $189(65 \%)$ & 0.4091 & $81(72 \%)$ & $81(72 \%)$ & 1.0000 \\
\hline Tumor disease & $68(55 \%)$ & $150(52 \%)$ & 0.5610 & $63(56 \%)$ & $48(43 \%)$ & 0.0450 \\
\hline Organ transplant & $16(13 \%)$ & $28(10 \%)$ & 0.4926 & $16(14 \%)$ & $7(6 \%)$ & 0.1323 \\
\hline Age & $65(13)$ & $66(13)$ & 0.3792 & $64(13)$ & $64(13)$ & 0.9309 \\
\hline BMI $\left[\mathrm{kg} / \mathrm{m}^{2}\right]$ & $29(8)$ & $29(9)$ & 0.9718 & $29(8)$ & $28(10)$ & 0.3679 \\
\hline \multicolumn{7}{|c|}{ Clinical condition } \\
\hline SOFA score & $13.5(3.3)$ & $12.6(2.9)$ & 0.0069 & $13.2(3.0)$ & $12.4(3.1)$ & 0.041 \\
\hline $\begin{array}{c}\text { APACHE II Score } \\
\text { GFR } \\
\text { (Cockroft-Gault) }\end{array}$ & $\begin{array}{l}30.3(6.4) \\
56(46)\end{array}$ & $\begin{array}{l}33.5(7.1) \\
56(40)\end{array}$ & $\begin{array}{c}<0.0001 \\
0.8994\end{array}$ & $\begin{array}{l}29.9(6.3) \\
60(47)\end{array}$ & $\begin{array}{l}33.7(6.6) \\
57(50)\end{array}$ & $\begin{array}{c}<0.0001 \\
0.6158\end{array}$ \\
\hline $\mathrm{VIS}[\mu \mathrm{g} / \mathrm{kg} / \mathrm{min}]$ & $68(56)$ & $51(35)$ & 0.0073 & $57(37)$ & $56(40)$ & 0.5616 \\
\hline Creatinine $[\mathrm{mg} / \mathrm{dL}]$ & $2.1(1.2)$ & $2.0(1.2)$ & 0.457 & $2.1(1.2)$ & $2.0(1.3)$ & 0.4988 \\
\hline $\begin{array}{l}\text { Serum lactate } \\
{[\mathrm{mg} / \mathrm{dL}]}\end{array}$ & $55(54)$ & $44(41)$ & 0.0428 & $51(49)$ & $46(47)$ & 0.5728 \\
\hline Leukocytes $[\mathrm{n} / \mathrm{mL}]$ & $17(12)$ & $17(12)$ & 0.6721 & $17(12)$ & $15(11)$ & 0.5173 \\
\hline CRP [mg/L] & $193(113)$ & $181(182)$ & 0.1036 & $194(110)$ & $193(256)$ & 0.1355 \\
\hline $\begin{array}{l}\text { Procalcitonin } \\
{[\mathrm{ng} / \mathrm{mL}]}\end{array}$ & $28(52)$ & $30(62)$ & 0.0534 & $26(45)$ & $30(50)$ & 0.7274 \\
\hline
\end{tabular}


Table 1. Cont.

\begin{tabular}{|c|c|c|c|c|c|c|}
\hline \multicolumn{4}{|c|}{ Baseline $(n=414)$} & \multicolumn{3}{|c|}{ Propensity-Score Matched $(n=224)$} \\
\hline \multicolumn{2}{|c|}{$\begin{array}{l}\text { Intermittent Bolus } \\
\quad(n=124)\end{array}$} & \multirow{2}{*}{$\begin{array}{c}\begin{array}{c}\text { Prolonged Infusion } \\
(n=290)\end{array} \\
10 \frac{\%(n)}{(28 / 290)}\end{array}$} & \multirow{2}{*}{$\begin{array}{c}p \text {-Value } \\
0.5\end{array}$} & \multirow{2}{*}{$\begin{array}{c}\begin{array}{c}\text { Intermittent Bolus } \\
(\boldsymbol{n}=\mathbf{1 1 2})\end{array} \\
14 \frac{\%(n)}{(16 / 112)}\end{array}$} & \multirow{2}{*}{$\begin{array}{c}\begin{array}{c}\text { Prolonged Infusion } \\
(n=112)\end{array} \\
6 \frac{\%(n)}{(7 / 112)}\end{array}$} & \multirow{2}{*}{$\begin{array}{c}p \text {-Value } \\
0.1323\end{array}$} \\
\hline SOT & $\begin{array}{l}\frac{\%(n)}{13} \\
(16 / 124)\end{array}$ & & & & & \\
\hline Liver & $63(10 / 16)$ & $46(13 / 28)$ & & $63(10 / 16)$ & $71(5 / 7)$ & \\
\hline Kidney & $19(3 / 16)$ & $36(10 / 28)$ & & $19(3 / 16)$ & $14(1 / 7)$ & \\
\hline Others & $19(3 / 16)$ & $18(5 / 28)$ & & $19(3 / 16)$ & $14(1 / 7)$ & \\
\hline Focus & & & $0.04 *$ & & & 0.108 \\
\hline Abdominal & $\begin{array}{c}66 \\
(82 / 124) \\
\end{array}$ & $76(221 / 290)$ & & $65(73 / 112)$ & $78(87 / 112)$ & \\
\hline Pulmonary & $\begin{array}{c}17 \\
(21 / 124)\end{array}$ & $11(31 / 290)$ & & $18(20 / 112)$ & $10(11 / 112)$ & \\
\hline UTI & $6(7 / 124)$ & $7(20 / 290)$ & & $5(6 / 112)$ & $6(7 / 112)$ & \\
\hline
\end{tabular}

Data are $n(\%)$ or mean (SD) unless otherwise specified. BMI: Body-mass-index. SOFA: Sequential Organ Failure Assessment score. APACHE II: Acute Physiology And Chronic Health Evaluation II. GFR: Glomerular filtration rate. VIS: Vasoactive-Inotropic score $(\mu \mathrm{g} / \mathrm{kg}$ per min) $=10 \times$ milrinon dose $(\mu \mathrm{g} / \mathrm{kg} / \mathrm{min})+10,000 \times$ vasopressin dose $(\mathrm{U} / \mathrm{kg} / \mathrm{min})+100 \times($ epinephrine dose $[\mu \mathrm{g} / \mathrm{kg} / \mathrm{min}]+$ norepinephrine dose $[\mu \mathrm{g} / \mathrm{kg} / \mathrm{min}])$. CRP: C-reactive Protein. SOT: solid organ transplantation. UTI: Urinary tract infection. * administration of: 1 or more vasopressor to maintain a mean arterial pressure of $65 \mathrm{mmHg}$ or higher + hydrocortisone $+\beta$-lactam antibiotic.
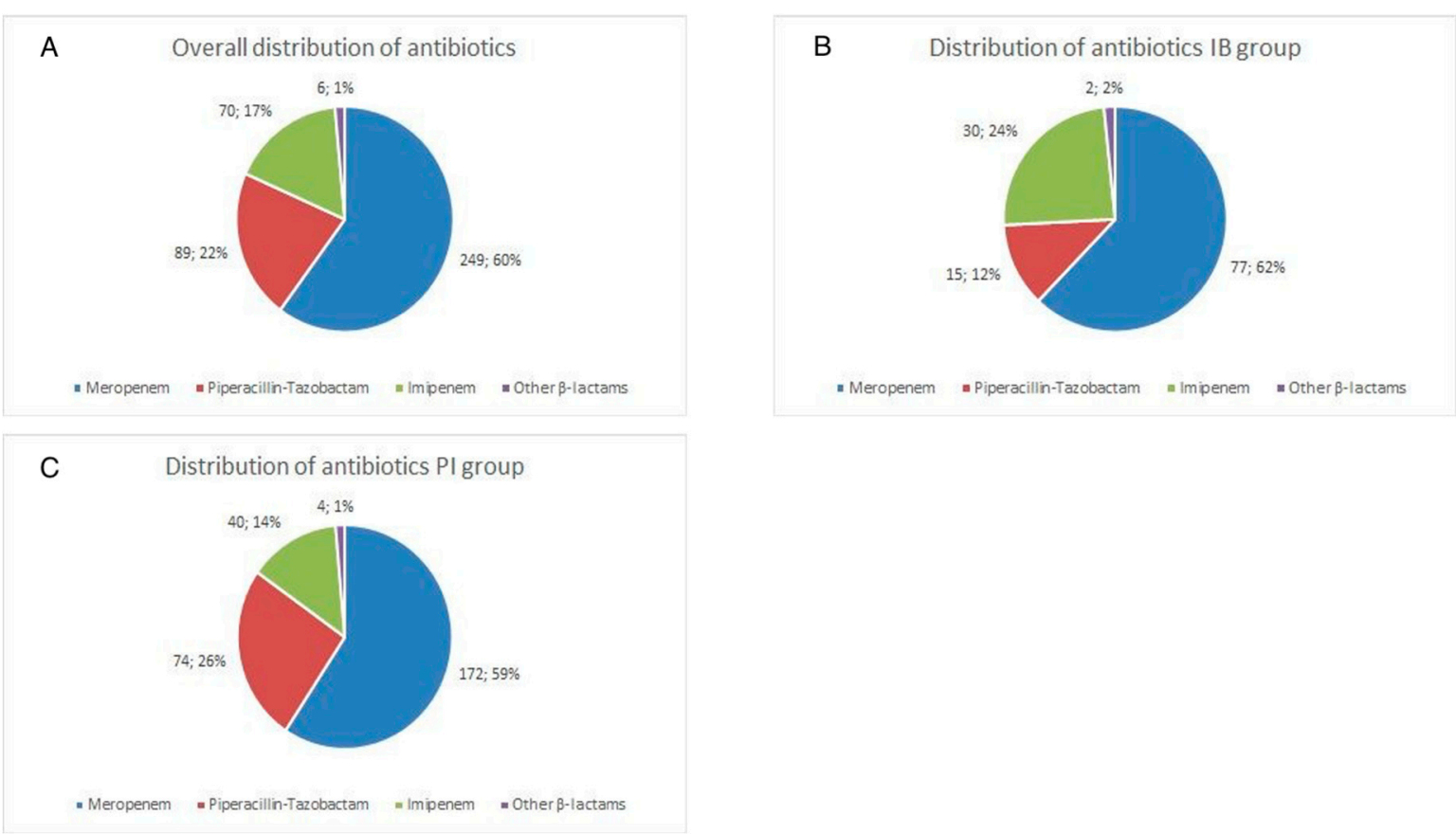

Figure 1. Distribution of Antibiotics in (A) Entire Cohort, (B) Intermittent bolus (IB) group and (C) prolonged infusion (PI) group.

One hundred and thirty-four (134) patients (46.2\%) of the PI group and 51 patients (41.1\%) of the IB group had already received antibiotic therapy prior to the onset of septic shock. Overall, carbapenems (meropenem 60\%, $n=249 / 414$, imipenem 17\%, $n=70 / 141$ ) and piperacillin/tazobactam $(22 \%, n=89 / 414)$ were the most frequently prescribed antibiotics. Compared to the IB cohort, patients in the PI group were given TZB more frequently $(12 \%, n=15 / 124$ vs. $26 \%, n=74 / 290$ (Figure $1 B, C) .29 .3 \%$ of patients of the PI group and $25.8 \%$ of patients of the IB group were additionally treated with antimycotics. $17.9 \%$ of 
patients of the PI group and $26.6 \%$ of patients of the IB group received antiviral medication. Consistent with the predominantly abdominal focus of infection, Gram-negative Enterobacterales and Gram-positive Enterococci were the leading pathogens (Table 2). In 36 of 414 patients $(8.7 \%)$ septic shock was treated without evidence of a causative pathogen.

Table 2. Pathogen distribution.

\begin{tabular}{|c|c|c|c|c|c|}
\hline & & \multicolumn{2}{|c|}{$\begin{array}{l}\text { Intermittent Bolus } \\
\quad(n=179)\end{array}$} & \multicolumn{2}{|c|}{$\begin{array}{l}\text { Prolonged Infusion } \\
\qquad(n=451)\end{array}$} \\
\hline & & $\begin{array}{l}\text { Lead Pathogen } \\
\quad(n=112)\end{array}$ & $\begin{array}{l}\text { Contributing Pathogen } \\
\qquad(n=67)\end{array}$ & $\begin{array}{l}\text { Lead Pathogen } \\
\quad(n=265)\end{array}$ & $\begin{array}{c}\text { Contributing Pathogen } \\
\qquad(n=186)\end{array}$ \\
\hline & & $\%(n)$ & $\%(n)$ & $\%(n)$ & $\%(n)$ \\
\hline \multirow{16}{*}{ 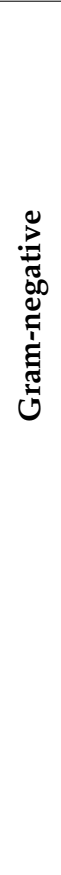 } & E. coli & $25(28)$ & $20.9(14)$ & $29.8(79)$ & $16.1(30)$ \\
\hline & MDR-E. coli ${ }^{*}$ & $1.8(2)$ & - & - & $0.5(1)$ \\
\hline & K. pneumoniae & $9(10)$ & $3(2)$ & $6.4(17)$ & $4.3(8)$ \\
\hline & MDR_K. pneumoniae * & none & $1.5(1)$ & $0.4(1)$ & - \\
\hline & K. oxytoca & $2.7(3)$ & - & $3.4(9)$ & $4.3(8)$ \\
\hline & Klebsiella spp. & - & - & $0.4(1)$ & $1.1(2)$ \\
\hline & Citrobacter freundii & $1.8(2)$ & $3(2)$ & $0.4(1)$ & $0.5(1)$ \\
\hline & Citrobacter spp. & $1.8(2)$ & - & - & $1.1(2)$ \\
\hline & Serratia marscescens & $2.7(3)$ & - & $0.8(2)$ & $0.5(1)$ \\
\hline & Serratia spp. & $0.9(1)$ & - & $0.4(1)$ & - \\
\hline & Proteus mirabilis & $2.7(3)$ & $1.5(1)$ & $4.5(12)$ & $1.6(3)$ \\
\hline & Proteus spp. & - & $1.5(1)$ & $0.4(1)$ & $0.5(1)$ \\
\hline & Enterobacter spp. & $3.6(4)$ & - & $2.3(6)$ & $5.4(10)$ \\
\hline & Pseudomonas aeruginosa & $6.3(7)$ & $6(4)$ & - & $5.9(11)$ \\
\hline & MDR-P. aeruginosa & $0.9(1)$ & $1.5(1)$ & - & - \\
\hline & Bacteroides fragilis & $3.6(4)$ & $7.5(5)$ & $1.5(4)$ & $1.1(2)$ \\
\hline \multirow{9}{*}{ 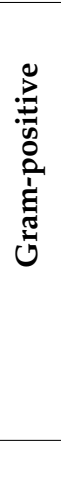 } & Enterococcus spp. & $4.5(5)$ & $10.4(7)$ & $3(8)$ & $5.9(11)$ \\
\hline & E. faecium & $9(10)$ & $13.4(9)$ & $10.9(29)$ & $6.5(12)$ \\
\hline & E. faecalis & - & $4.5(3)$ & $1.1(3)$ & $3.8(7)$ \\
\hline & VRE & $8(9)$ & $3(2)$ & $7.5(20)$ & $10.8(20)$ \\
\hline & Staphylococcus spp. & $7.1(8)$ & $4.5(3)$ & $7.5(25)$ & $4.3(8)$ \\
\hline & MRSA & $0.9(1)$ & $3(2)$ & - & - \\
\hline & Streptococcus spp. & $1.8(2)$ & $1.5(1)$ & $3.4(9)$ & $4.3(8)$ \\
\hline & Clostridium spp. & $0.9(1)$ & $1.5(1)$ & $2.6(7)$ & $1.6(3)$ \\
\hline & Others & \multicolumn{2}{|c|}{$46(83 / 179)$} & \multicolumn{2}{|c|}{$15(67 / 451)$} \\
\hline
\end{tabular}

Data are given as relative frequencies (\%) and absolute numbers $(n)$. Lead pathogens were considered the primarily causative pathogen identified. Overall, no pathogen was detected in 8.7\% (36/414) of cases (subgroups: IB 10.5\% (13/124), PI: 7.9\% (23/290)) * Combined resistance towards 3 rd-generation cephalosporins \& fluoroquinolones ${ }^{\#}$ Combined resistances towards piperacillin/tazobactam, ceftazidime, fluoroquinolones \& carbapenems.

\subsection{Primary Outcome}

Prolonged $\beta$-Lactam Administration Was Associated with Lower Mortality

Unmatched analysis of the entire cohort suggested a significantly lower 30-day $(-13.8 \%, p=0.0097)$ and 90 -day-mortality $(-15 \%, p=0.005)$ in patients receiving PI of the $\beta$-lactams. Survival estimates using a Kaplan-Meier-Plot of 30d-mortality (Figure 2) shows early partitioning of survival probability lines. The propensity-score matched anal- 
ysis of the cohorts led to non-significant, however clinically still relevant, differences in

30 day-( $-10.7 \%)$, 90 day-(-9.8\%), ICU-( $-9.9 \%)$, and hospital-mortality $(-11.6 \%)$ (Table 3$)$.

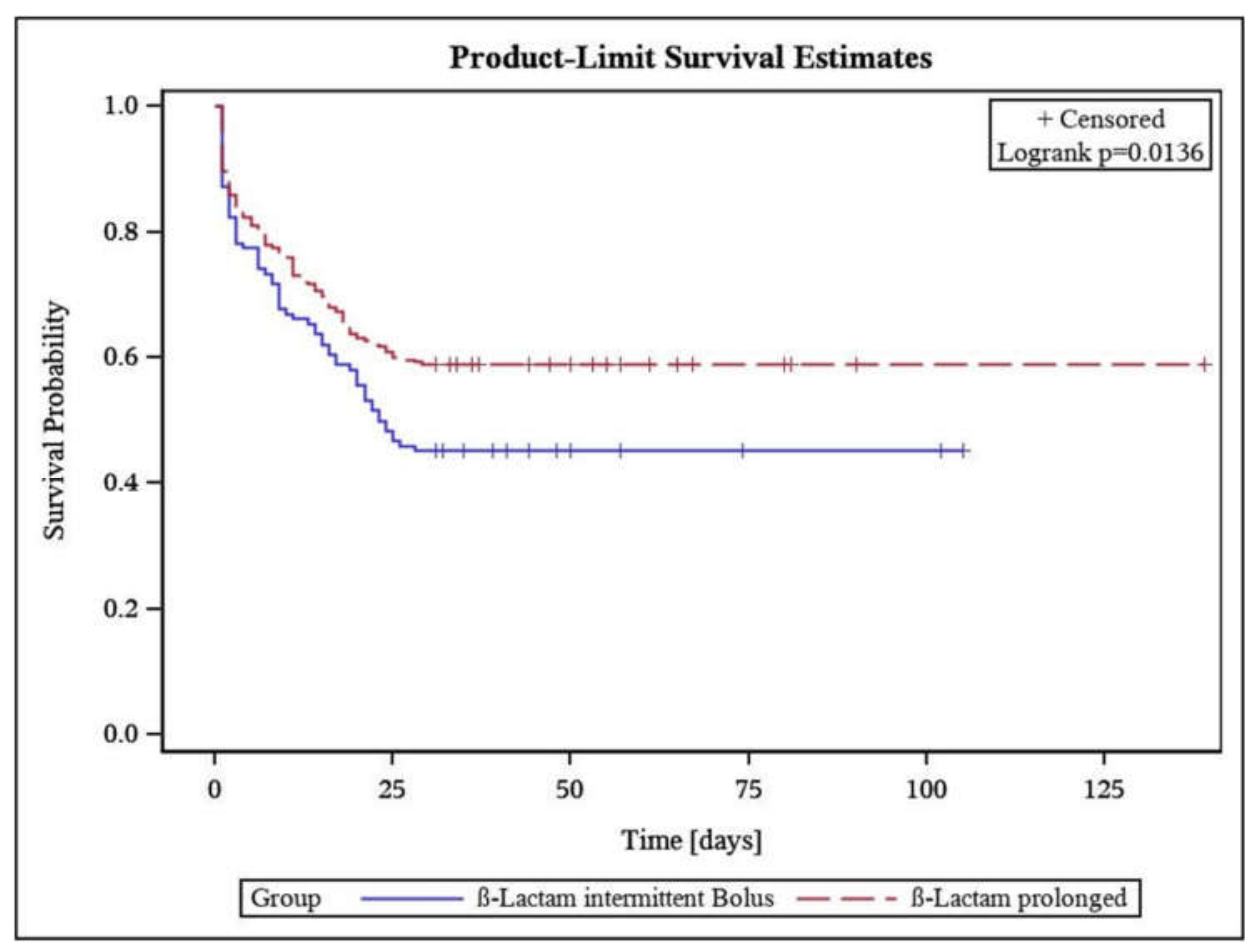

Figure 2. Kaplan-Meier product-limit survival estimates in intermittent bolus and prolonged infusion group.

Table 3. Primary endpoints in baseline cohort and propensity-score matched patients.

\begin{tabular}{ccccccccc}
\hline \multicolumn{7}{c}{ Baseline $(n=414)$} \\
\multicolumn{7}{c}{ Propensity-Score Matched $(n=\mathbf{2 2 4})$} \\
\hline \multicolumn{2}{c}{ Intermittent Bolus } & $\begin{array}{c}\text { Prolonged } \\
\text { Infusion }\end{array}$ & $\mathbf{d} \%$ & $p$ & $\begin{array}{c}\text { Intermittent } \\
\text { Bolus }\end{array}$ & $\begin{array}{c}\text { Prolonged } \\
\text { Infusion }\end{array}$ & $\begin{array}{c}\mathbf{d} \% \\
p\end{array}$ \\
\hline $\begin{array}{c}\text { Hospital mortality, } \\
\%(n)\end{array}$ & $\begin{array}{c}64.5 \\
(80 / 124)\end{array}$ & $48.3(140 / 290)$ & $\mathbf{1 6 . 2}$ & $\mathbf{0 . 0 0 2 4}$ & $62.5(70 / 112)$ & $50.9(57 / 112)$ & $\mathbf{1 1 . 6}$ & n.s. \\
\hline $\begin{array}{c}\text { ICU mortality, } \\
\%(n)\end{array}$ & $\begin{array}{c}57.3 \\
(71 / 124)\end{array}$ & $43.5(126 / 290)$ & $\mathbf{1 3 . 8}$ & $\mathbf{0 . 0 1}$ & $54.5(61 / 112)$ & $44.6(50 / 112)$ & $\mathbf{9 . 9}$ & n.s. \\
\hline $\begin{array}{c}\text { 30-day mortality } \\
\%(n)\end{array}$ & $\begin{array}{c}54.8 \\
(68 / 124)\end{array}$ & $41(119 / 290)$ & $\mathbf{1 3 . 8}$ & $\mathbf{0 . 0 0 9 7}$ & $52.7(59 / 112)$ & $42(47 / 112)$ & $\mathbf{1 0 . 7}$ & n.s. \\
\hline $\begin{array}{c}\text { 90-day mortality } \\
\%(n)\end{array}$ & $\begin{array}{c}62.9 \\
(78 / 124)\end{array}$ & $47.9(139 / 290)$ & $\mathbf{1 5}$ & $\mathbf{0 . 0 0 5}$ & $60.7(68 / 112)$ & $50.9(57 / 112)$ & $\mathbf{9 . 8}$ & n.s. \\
\hline
\end{tabular}

Data are \%(n) unless other specified. IB: intermittent bolus. PI: prolonged infusion. d\%: percentage difference. ICU: Intensive Care Unit. n.s.: not significant.

\subsection{Secondary Outcome Parameters}

3.3.1. Prolonged $\beta$-Lactam Administration Was Associated with Shorter Duration of Invasive Ventilation

Patients treated with PI also had a shorter ICU stay in the unmatched (IB $15.8 \mathrm{~d}$ [19.4 d] vs. PI $13.6 \mathrm{~d}$ [16.1 d]; 0.219) and matched analysis (IB $17.1 \mathrm{~d}$ [19.9 d] vs. PI $13.5 \mathrm{~d}$ [15.7 d]; 0.139 ), the difference was not statistically significant in both analyses (Figure 3A). PI of $\beta$-lactams was associated with significantly shorter mean duration of invasive ventilation in both unmatched (IB $13.2 \mathrm{~d}$ [16.2 d] vs. PI $8.4 \mathrm{~d}$ [10.1 d]; $p<0.001$ ) and propensity-score matched analysis (IB $14.2 \mathrm{~d}$ [16.6 d] vs. PI $8.3 \mathrm{~d}$ [10.6 d]; $p=0.002$ ) (Figure 3B). 


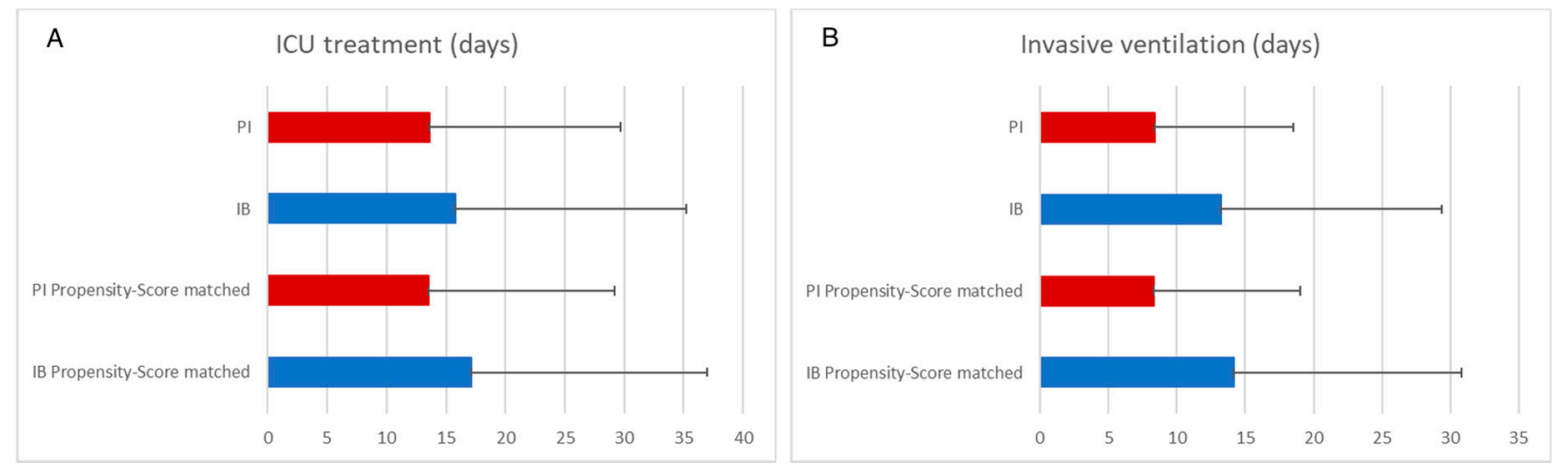

Figure 3. Secondary endpoints. Plot bars show mean values, error bars the standard deviation. PI: prolonged infusion. IB: intermittent bolus. (A) ICU treatment; (B) Invasive ventilation.

\subsubsection{PI of $\beta$-Lactams Was Associated with Faster Improvement of Organ Failure}

Figure 4A-F depict the course of other parameters clinically used to predict responses to effective sepsis therapy. While the decline in laboratory infection surrogates (C-reactive protein [CRP] and procalcitonin [PCT]), APACHE II score and vasopressor dependence (VIS) did not significantly differ between both groups. PI of $\beta$-lactam antibiotics was associated with a stronger decrease of the SOFA score over a period of 14 days.

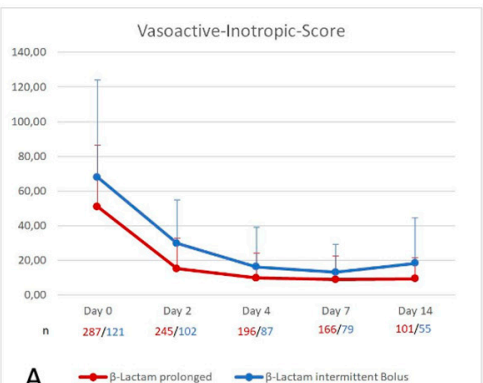

A

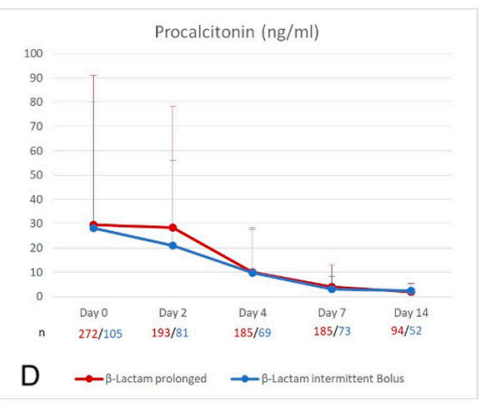

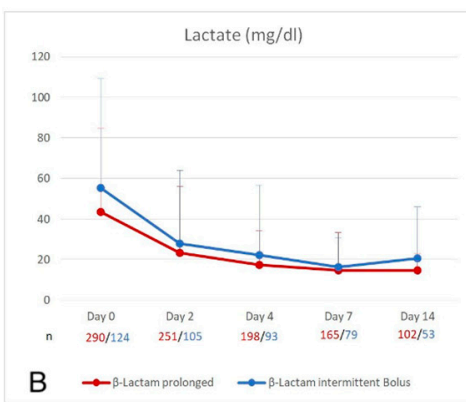

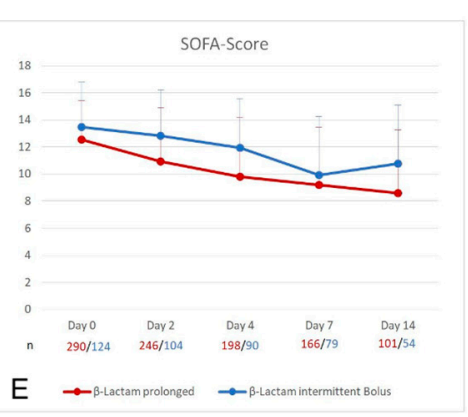

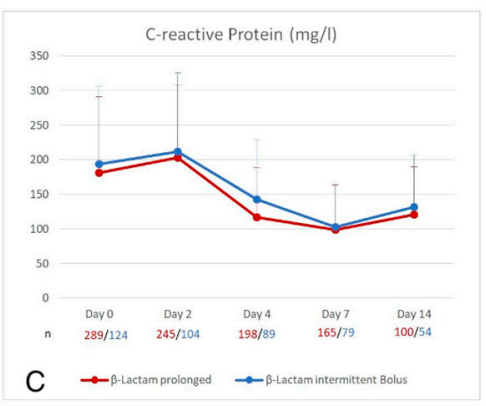

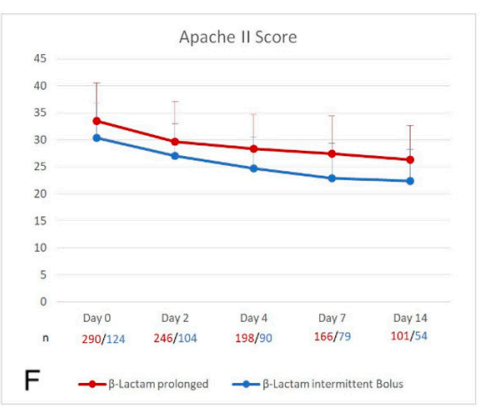

Figure 4. Course of Vasoactive-inotropic-score (A), Lactate (B), C-reactive protein (C), Procalcitonin (D), SOFA-Score (E), APACHE II Score (F) in baseline cohort over a 14 day observation period.

Number $(n)$ of patients is presented below graph in red for the prolonged infusion and blue for the intermittent bolus group. SOFA Score: Sepsis-related organ failure assessment score. APACHE II: Acute Physiology And Chronic Health Evaluation II.

\section{Discussion}

This retrospective study investigated the effects of prolonged infused $\beta$-lactams on mortality of patients in septic shock in a German intensive care unit between 2015 and 2020. Critically ill patients with sepsis are prone to insufficiently low serum concentrations and consecutive treatment failure because of unique alterations of $\beta$-lactam PK $[11,13,14,30-32]$. 
PI of $\beta$-lactams evolved as a reaction to a better understanding of the PK/PD index of this group of antibiotics whereby prolongation of the $\mathrm{fT}_{>\mathrm{MIC} / \mathrm{ECOFF}}$ subsequently leads to a better antimicrobial exposure of the causative pathogens [33]. Previous investigations already suggested lower mortality rates and better clinical outcome using extended infusions in adults [23-25,34-36] and pediatric patients [37]. These effects are attributed to improved PK target attainment during extended infusions [36,38-40]. Critical patients included in the study of Roberts [22] and Abdul-Aziz et al. [23] had median SOFA scores of only 6 (IQR 3-9) and had varying sites of infection. Abdul-Aziz and co-workers [23] demonstrated significantly lower mortality for PI of $\beta$-lactams in patients with a SOFA score $\geq 9$ and those with pneumonia. We analyzed a cohort of 414 severely ill patients with predominantly abdominal septic shock with mean SOFA scores of 13 predicting an a priori high mortality [41]. The monocentric nature of the study allowed for good comparability as depicted in the baseline characteristics given in Table 1. Contrary to Rhodes et al. [24], we exclusively evaluated only prolonged infusions of $\beta$-lactams. As a primary outcome measure, we found a significant reduction in mortality for the PI group. To control for interfering clinical properties, we performed a propensity-score matching and re-analyzed the primary outcome measure in the matched cohorts. While differences in mortality did not reach statistical significance, we still found markedly lower mortality rates when $\beta$-lactams were administered as a PI. Because of the unequal number of patients in both groups, generating pairs of patients as a prerequisite of matching was followed by a loss of about $50 \%$ of patients making it unlikely for a chi-square test to reach the significance level. Decreasing mortality rates by $10 \%$ in a cohort of patients with high probability of death—statistically significant or not-is, of utmost importance to patients and clinicians. Kaplan-Meyer estimates of survival show an early divergence of survival curves, suggesting a significant impact $(p=0.014)$ of PI on median survival probability. These findings strongly support the conclusion of a recently published review of AbdulAziz and colleagues whereby PI of $\beta$-lactams might be especially important for critically ill/immunocompromised patients and those who are more likely to have less susceptible Gram-negative infections [42]. Responding to the revised SSC guidelines [4], we changed our local sepsis protocol in 2017 which most likely explains that patients in the PI group received TZB considerably more often (26\%) as between $2015-2017(12 \%)$ while prescription patterns of meropenem did not change. As can be seen in Table 2, major changes in causative pathogens or an increase of infections caused by multidrug-resistant bacteria as a reason can be excluded. We further found a reduction of duration of invasive ventilation for patients in the PI group. We would like to argue that these effects are in line with prospective investigations highlighting the role of focus control and adequate antibiotic treatment $[3,5,6,43,44]$. On the other hand, uncontrolled or prolonged abdominal infection is accompanied by a gastrointestinal paralysis with subsequent distension of intestinal loops leading to a restrictive airway and higher incidence of micro-aspiration [45,46]. An interesting finding of our study is, that inflammatory markers like C-reactive protein and procalcitonin showed similar courses (Figure 4C,D) although PI was associated with lower mortality. An explanation is that CRP is an unreliable marker of infection in patients on surgical ICUs as CRP levels can vary as a consequence of surgical trauma or liver insufficiency. PCT is an inflammatory marker mainly well evaluated for (lower) respiratory tract infections and a general marker to distinguish bacterial from non-bacterial infections. While PCT is routinely used in abdominal infections its role in guiding therapy is still unclear [47].In what way the gut-lung axis and its role in immunomodulation contributes remains to be investigated [48]. Unlike previous prospective studies [38,39], we included patients on RRT or/and hepatic dysfunction. RRT may have unpredictable effects on serum concentrations of hydrophilic $\beta$-lactams and PK target attainment, according to recently published work [36,49]. We decided against a detailed evaluation of the subgroup of patients receiving RRT for two reasons. Firstly, serum concentrations were not available, and the study did not focus on PK effects. Secondly, we intended to analyze crude overall effect of a representative cohort of septic shock patients. With a fraction of $43 \%$ (IB) and 
$40 \%$ (PI) both cohorts show a rather high fraction of patients in need for temporal RRT. The high rates of RRT result from the inclusion criteria that focused on patients in septic shock. Further, baseline characteristics imply that the evaluated cohort constituted of older patients (IB: 65 y [13]; PI: 66 [13]) with high VIS.

The study has some limitations. Data were drawn from a single center and comprised an exclusive cohort of patients with predominantly abdominal septic shock. Though our findings are in line with other prospective studies, findings cannot readily be generalized to other cohorts. Although we report microbiological data, resistance data and MICs were not available. Also, serum concentrations of $\beta$-lactams were not measured. Attaining PK targets is advised during treatment of critically ill patients [19]. Unfortunately, our data do not allow to link outcome (mortality) to specific PK-targets. Until 2020, we did not implement TDM-guided dose optimization in our department and adjusted $\beta$-lactam doses according to the manufacturers' recommendation. Hence, we were not able to either investigate $\beta$-lactam toxicity [50-53] nor could we connect serum concentrations to outcome. Against this background, we are expecting the results of two interesting studies: The German TARGET study by Hagel et al. [54] (DRKS00011159) investigates the impact of TDM-guided dose adjustments in the ICU on survival of patients with sepsis and septic shock while the Australian BLING 3 study (NCT03213990) is still recruiting patients to evaluate clinical effects of continuously infused $\beta$-lactams versus intermittent bolus application.

\section{Conclusions}

The present study strongly endorses existing evidence of pivotal prospective studies and meta-analyses favoring PI of $\beta$-lactams in critically ill patients. PI was associated with a clinically relevant reduction of mortality in a severely ill subpopulation of ICU patients with septic shock and a shorter duration of ventilation. Further studies are necessary to investigate the effect of TDM-guided dose-optimization in addition to PI.

Author Contributions: Conceptualization, D.C.R., M.D.; F.C.F.S., M.O.F.; T.B. (Thomas Bruckner); D.S., U.C.; S.K., T.H., T.B. (Thorsten Brenner), A.B. and M.A.W.; Formal analysis, D.C.R., M.D. and T.B. (Thomas Bruckner); Investigation, D.C.R., M.D., L.D.L., M.O.F., D.S., U.C. and S.K; Methodology, D.C.R., M.D., T.B (Thomas Bruckner)., T.H., T.B. (Thorsten Brenner), A.B. and M.A.W.; Project administration, D.C.R., and M.D.; Resources, T.B. (Thorsten Brenner), A.B. and M.A.W.; Supervision, T.B. (Thorsten Brenner), A.B. and M.A.W.; Visualization, D.C.R., M.D., L.D.L. and F.C.F.S.; Writingoriginal draft, D.C.R. and M.D.; Writing-review and editing, F.C.F.S., M.O.F., D.S., U.C., S.K., T.H., T.B., A.B. and M.A.W. All authors have read and agreed to the published version of the manuscript.

Funding: The authors did not receive external funding.

Institutional Review Board Statement: The study was conducted according to the guidelines of the Declaration of Helsinki, and approved by the Ethics Committee of the medical faculty of the University of Heidelberg (reference number: S-586/2020, 18.08.2020).

Informed Consent Statement: This manuscript was waived due to the retrospective study design.

Data Availability Statement: Data are made available on reasonable request through the principal investigators.

Conflicts of Interest: Richter D. C. has received refunding of travel expenses from Gilead Sciences Inc., Astellas Pharma, MSD and Pfizer; Schmitt F.C.F. received honoraria for lectures from CSL Behring $\mathrm{GmbH}$. Furthermore, he received funding from the Deutschen Zentrum für Infektionsforschung (DZIF), Heidelberg Foundation of Surgery and Philips Medizin Systeme Böblingen GmbH; Brenner Th. received honoraria for lectures from Pfizer Pharma GmbH, Biotest AG, Baxter Deutschland $\mathrm{GmbH}$, Schöchl medical education $\mathrm{GmbH}$, Boehringer Ingelheim Pharma GmbH, CSL Behring $\mathrm{GmbH}$, Astellas Pharma GmbH, B. Braun Melsungen AG and MSD Sharp \& Dohme GmbH. Furthermore, he received funding from the Innovation Fund of the Federal Joint Committee (G-BA), Deutsche Forschungsgemeinschaft (DFG), Heidelberg Foundation of Surgery, Dietmar Hopp Stiftung and Stiftung Universitätsmedizin Essen; Brinkmann A. has received lecture fees and/or refunding of travel expenses from: Grünenthal GmbH, Pfizer Pharma GmbH, Fresenius Medical Care (FMC), 
Niedersächsisches Landesgesundheitsamt, LADR-Laboratory Bremen, Laborbetriebsgesellschaft Dr. Dirkes-Ker- sting GmbH, Gelsenkirchen, Laboratory Volkmann, Karlsruhe; Weigand M. A.: Lecture fees Shionogi, MSD, Pfizer; Advisory Board MSD, Gilead, Shionogi, Eumedica, Biotest, Sedana.

\section{References}

1. Fleischmann, C.; Scherag, A.; Adhikari, N.K.J.; Hartog, C.S.; Tsaganos, T.; Schlattman, P.; Angus, D.C.; Reinhart, K.; International Forum of Acute Care Trialists. Assessment of global incidence and mortality of hospital-treated sepsis. Current estimates and limitations. Am. J. Respir. Crit. Care Med. 2016, 193, 259-272. [CrossRef] [PubMed]

2. Fleischmann, C.; Thomas-Rueddel, D.O.; Hartmann, M.; Hartog, C.S.; Welte, T.; Heublein, S.; Dennler, U.; Reinhart, K. Hospital incidence and mortality rates of sepsis. Dtsch. Aerzteblatt Int. 2016, 113, 159-166. [CrossRef]

3. Group, S.C.C.T. Incidence of severe sepsis and septic shock in German intensive care units: The prospective, multicentre INSEP study. Intensive Care Med. 2016, 42, 1980-1989.

4. Rhodes, A.; Evans, L.E.; Alhazzani, W.; Levy, M.M.; Antonelly, M.; Ferrer, R.; Kumar, A.; Sevransky, J.E.; Sprung, C.L.; Nunally, M.E.; et al. Surviving sepsis campaign: International guidelines for management of sepsis and septic shock: 2016. Intensive Care Med. 2017, 43, 304-377. [CrossRef] [PubMed]

5. Kumar, A.; Roberts, D.; Wood, K.E.; Light, B.; Parrillo, J.E.; Sharma, S.; Suppes, R.; Feinstein, D.; Zannoti, S.; Taiberg, L.; et al. Duration of hypotension before initiation of effective antimicrobial therapy is the critical determinant of survival in human septic shock. Crit. Care Med. 2006, 34, 1589-1596. [CrossRef]

6. Ferrer, R.; Martin-Loeches, I.; Phillips, G.; Osborn, T.M.; Townsend, S.; Dellinger, R.P.; Artigas, A.; Schorr, C.; Levy, M.M. Empiric antibiotic treatment reduces mortality in severe sepsis and septic shock from the first hour: Results from a guideline-based performance improvement program. Crit. Care Med. 2014, 42, 1749-1755. [CrossRef]

7. Díaz-Martín, A.; Martínez-González, M.L.; Ferrer, R.; Ortiz-Leyba, C.; Piacentini, E.; Lopez-Pueyo, M.J.; Martín-Loeches, I.; Levy, M.M.; Artigas, A.; Garnacho-Montero, J.; et al. Antibiotic prescription patterns in the empiric therapy of severe sepsis: Combination of antimicrobials with different mechanisms of action reduces mortality. Crit. Care 2012, 16, R223. [CrossRef]

8. Magill, S.S.; Edwards, J.R.; Beldavs, Z.G.; Dumyati, G.; Janelle, S.J.; Kainer, M.A.; Lynfield, R.; Nadle, J.; Neuhauser, M.M.; Ray, S.M.; et al. Prevalence of antimicrobial use in US acute care hospitals, May-September 2011. JAMA 2014, 312, 1438-1446. [CrossRef]

9. Roberts, J.A.; Abdul-Aziz, M.H.; Lipman, J.; Mouton, J.W.; Vinks, A.A.; Felton, T.W.; Hope, W.W.; Farkas, A.; Neely, M.N.; Schentag, J.J.; et al. Individualised antibiotic dosing for patients who are critically ill: Challenges and potential solutions. Lancet Infect. Dis. 2014, 14, 498-509. [CrossRef]

10. Claus, B.O.; Hoste, E.A.; Colpaert, K.; Robays, H.; Decruyenaere, J.; De Waele, J.J. Augmented renal clearance is a common finding with worse clinical outcome in critically ill patients receiving antimicrobial therapy. J. Crit. Care 2013, 28, 695-700. [CrossRef] [PubMed]

11. Sime, F.; Udy, A.; Roberts, J.A. Augmented renal clearance in critically ill patients: Etiology, definition and implications for beta-lactam dose optimization. Curr. Opin. Pharmacol. 2015, 24, 1-6. [CrossRef]

12. Udy, A.A.; Varghese, J.M.; Altukroni, M.; Briscoe, S.; McWhinney, B.; Ungerer, J.P.; Lipman, J.; Roberts, J.A. Subtherapeutic initial beta-lactam concentrations in select critically ill patients: Association between augmented renal clearance and low trough drug concentrations. Chest 2012, 142, 30-39. [CrossRef]

13. Udy, A.A.; Lipman, J.; Jarrett, P.; Klein, K.; Wallis, S.C.; Patel, K.; Kirkpatrick, C.M.; Kruger, P.S.; Paterson, D.L.; Roberts, M.S.; et al. Are standard doses of piperacillin sufficient for critically ill patients with augmented creatinine clearance? Crit. Care 2015, 19, 28. [CrossRef]

14. Petersson, J.; Giske, C.; Eliasson, E. Standard dosing of piperacillin and meropenem fail to achieve adequate plasma concentrations in ICU patients. Acta Anaesthesiol. Scand. 2016, 60, 1425-1436. [CrossRef] [PubMed]

15. Zander, J.; Döbbeler, G.; Nagel, D.; Maier, B.; Scharf, C.; Huseyn-Zada, M.; Jung, J.; Frey, L.; Vogeser, M.; Zoller, M. Piperacillin concentration in relation to therapeutic range in critically ill patients-A prospective observational study. Crit. Care 2016, 20, 79. [CrossRef]

16. De Waele, J.J.; Lipman, J.; Akova, M.; Bassetti, M.; Dimopoulos, G.; Kaukonen, M.; Koulenti, D.; Martin, C.; Montravers, P.; Rello, J.; et al. Risk factors for target non-attainment during empirical treatment with $\beta$-lactam antibiotics in critically ill patients. Intensive Care Med. 2014, 40, 1340-1351. [CrossRef] [PubMed]

17. Gonçalves-Pereira, J.; Silva, N.E.; Mateus, A.; Pinho, C.; Póvoa, P. Assessment of pharmacokinetic changes of meropenem during therapy in septic critically ill patients. BMC Pharmacol. Toxicol. 2014, 15, 21. [CrossRef] [PubMed]

18. Kalil, A.C.; Metersky, M.L.; Klompas, M.; Muscedere, J.; Sweeney, D.A.; Palmer, L.B.; Napolitano, L.M.; O'Grady, N.; Bartlett, J.G.; Carratalà, J.; et al. Management of adults with hospital-acquired and ventilator-associated pneumonia: 2016 clinical practice guidelines by the Infectious Diseases Society of America and the American Thoracic Society. Clin. Infect. Dis. 2016, 63, e61-e111. [CrossRef]

19. Abdul-Aziz, M.H.; The Infection Section of European Society of Intensive Care Medicine (ESICM); Alffenaar, J.-W.C.; Bassetti, M.; Bracht, H.; Dimopoulos, G.; Marriott, D.; Neely, M.N.; Paiva, J.-A.; Pea, F.; et al. Antimicrobial therapeutic drug monitoring in critically ill adult patients: A Position Paper\#. Intensive Care Med. 2020, 46, 1127-1153. [CrossRef] [PubMed] 
20. Veiga, R.P.; Paiva, J.-A. Pharmacokinetics-pharmacodynamics issues relevant for the clinical use of beta-lactam antibiotics in critically ill patients. Crit. Care 2018, 22, 1-34. [CrossRef] [PubMed]

21. Sinnollareddy, M.G.; Roberts, M.S.; Lipman, J.; Roberts, J.A. $\beta$-L actam pharmacokinetics and pharmacodynamics in critically ill patients and strategies for dose optimization: A structured review. Clin. Exp. Pharmacol. Physiol. 2012, 39, 489-496. [CrossRef]

22. Roberts, J.A.; Paul, S.K.; Akova, M.; Bassetti, M.; De Waele, J.J.; Dimopoulos, G.; Kaukonen, K.-M.; Koulenti, D.; Martin, C.; Montravers, P.; et al. DALI: Defining antibiotic levels in intensive care unit patients: Are current beta-lactam antibiotic doses sufficient for critically ill patients? Clin. Infect. Dis. 2014, 58, 1072-1083. [CrossRef]

23. Abdul-Aziz, M.H.; Lipman, J.; Akova, M.; Bassetti, M.; De Waele, J.J.; Dimopoulos, G.; Dulhunty, J.; Kaukonen, K.-M.; Koulenti, D.; Martin, C.; et al. Is prolonged infusion of piperacillin/tazobactam and meropenem in critically ill patients associated with improved pharmacokinetic/pharmacodynamic and patient outcomes? An observation from the Defining Antibiotic Levels in Intensive care unit patients (DALI) cohort. J. Antimicrob. Chemother. 2015, 71, 196-207. [CrossRef]

24. Rhodes, N.J.; Liu, J.; O’Donnell, J.N.; Dulhunty, J.M.; Abdul-Aziz, M.H.; Berko, P.Y.; Nadler, B.; Lipman, J.; Roberts, J.A. Prolonged infusion piperacillin-tazobactam decreases mortality and improves outcomes in severely ill patients: Results of a systematic review and meta-analysis. Crit. Care Med. 2018, 46, 236-243. [CrossRef] [PubMed]

25. Falagas, M.E.; Tansarli, G.S.; Ikawa, K.; Vardakas, K.Z. Clinical outcomes with extended or continuous versus short-term intravenous infusion of carbapenems and piperacillin/tazobactam: A systematic review and meta-analysis. Clin. Infect. Dis. 2012, 56, 272-282. [CrossRef] [PubMed]

26. Brunkhorst, F.; Weigand, M.A.; Pletz, M.; Gastmeier, P.; Lemmen, S.W.; Meier-Hellmann, A.; Ragaller, M.; Weyland, A.; Marx, G.; Bucher, M.; et al. S3-leitlinie sepsis-prävention, diagnose, therapie und nachsorge. Med. Klin. Intensivmed. Notf. 2020, 115, 37-109. [CrossRef] [PubMed]

27. Butts, R.J.; Scheurer, M.A.; Atz, A.M.; Zyblewski, S.C.; Hulsey, T.C.; Bradley, S.M.; Graham, E.M. Comparison of maximum vasoactive inotropic score and low cardiac output syndrome as markers of early postoperative outcomes after neonatal cardiac surgery. Pediatr. Cardiol. 2012, 33, 633-638. [CrossRef] [PubMed]

28. Vincent, J.-L.; Moreno, R.; Takala, J.; Willats, S.; De Mendonça, A.; Bruining, H.; Reinhart, C.K.; Suter, P.M.; Thijs, L.G. The SOFA (Sepsis-related Organ Failure Assessment) score to describe organ dysfunction/failure. Intensive Care Med. 1996, 22, 707-710. [CrossRef]

29. Knaus, W.A.; Draper, E.A.; Wagner, D.P.; Zimmerman, J.E. APACHE II: A severity of disease classification system. Crit. Care Med. 1985, 13, 818-829. [CrossRef]

30. Alobaid, A.S.; Hites, M.; Lipman, J.; Taccone, F.S.; Roberts, J.A. Effect of obesity on the pharmacokinetics of antimicrobials in critically ill patients: A structured review. Int. J. Antimicrob. Agents 2016, 47, 259-268. [CrossRef]

31. Cotta, M.; Roberts, J.; Lipman, J. We need to optimize piperacillin-tazobactam dosing in critically ill patients—But how? Crit. Care 2016, 20, 163. [CrossRef]

32. Brinkmann, A.; Röhr, A.C.; Köberer, A.; Fuchs, T.; Krüger, W.A.; König, C.; Richter, D.; Weingand, M.A.; Frey, O.R. Adäquate antiinfektivatherapie. Der Anaesthesist 2018, 67, 461-476. [CrossRef]

33. Craig, W.A. State-of-the-art clinical article: Pharmacokinetic/pharmacodynamic parameters: Rationale for antibacterial dosing of mice and men. Clin. Infect. Dis. 1998, 26, 1-10. [CrossRef] [PubMed]

34. Roberts, J.A.; Abdul-Aziz, M.-H.; Davis, J.S.; Dulhunty, J.M.; Cota, M.O.; Myburgh, J.; Bellomo, R.; Lipman, J. Continuous versus Intermittent beta-lactam infusion in severe sepsis: A meta-analysis of individual patient data from randomized trials. Am. J. Respir. Crit. Care Med. 2016, 194, 681-691. [CrossRef]

35. Vardakas, K.Z.; Voulgaris, G.L.; Maliaros, A.; Samonis, G.; Falagas, M.E. Prolonged versus short-term intravenous infusion of antipseudomonal $\beta$-lactams for patients with sepsis: A systematic review and meta-analysis of randomised trials. Lancet Infect. Dis. 2018, 18, 108-120. [CrossRef]

36. Richter, D.C.; Frey, O.; Röhr, A.; Roberts, J.A.; Köberer, A.; Fuchs, T.; Papadimas, N.; Heinzel-Gutenbrunner, M.; Brenner, T.; Lichtenstern, C.; et al. Therapeutic drug monitoring-guided continuous infusion of piperacillin/tazobactam significantly improves pharmacokinetic target attainment in critically ill patients: A retrospective analysis of four years of clinical experience. Infection 2019, 47, 1001-1011. [CrossRef]

37. Zembles, T.N.; Schortemeyer, R.; Kuhn, E.M.; Bushee, G.; Thompson, N.E.; Mitchell, M.L. Extended infusion of beta-lactams is associated with improved outcomes in pediatric patients. J. Pediatr. Pharmacol. Ther. 2021, 26, 187-193. [CrossRef] [PubMed]

38. Abdul-Aziz, M.H.; Sulaiman, H.; Nor, M.B.M.; Rai, V.; Wong, K.K.; Hasan, M.S.; Rahman, A.N.A.; Jamal, J.A.; Wallis, S.C.; Lipman, J.; et al. Beta-lactam infusion in severe sepsis (BLISS): A prospective, two-centre, open-labelled randomised controlled trial of continuous versus intermittent beta-lactam infusion in critically ill patients with severe sepsis. Intensive Care Med. 2016, 42, 1535-1545. [CrossRef] [PubMed]

39. Dulhunty, J.M.; Roberts, J.A.; Davis, J.S.; Webb, S.A.R.; Bellomo, R.; Gomersall, C.; Shirwadkar, C.; Eastwood, G.M.; Myburgh, J.; Paterson, D.; et al. A multicenter randomized trial of continuous versus intermittent $\beta$-lactam infusion in severe sepsis. Am. J. Respir. Crit. Care Med. 2015, 192, 1298-1305. [CrossRef]

40. Dulhunty, J.M.; Roberts, J.; Davis, J.S.; Webb, S.A.R.; Bellomo, R.; Gomersall, C.; Shirwadkar, C.; Eastwood, G.M.; Myburgh, J.; Paterson, D.; et al. Continuous infusion of beta-lactam antibiotics in severe sepsis: A Multicenter double-blind, randomized controlled trial. Clin. Infect. Dis. 2012, 56, 236-244. [CrossRef] [PubMed] 
41. Jones, A.E.; Trzeciak, S.; Kline, J.A. The Sequential Organ Failure Assessment score for predicting outcome in patients with severe sepsis and evidence of hypoperfusion at the time of emergency department presentation*. Crit. Care Med. 2009, 37, 1649-1654. [CrossRef] [PubMed]

42. Abdul-Aziz, M.H.; Portunato, F.; Roberts, J.A. Prolonged infusion of beta-lactam antibiotics for Gram-negative infections: Rationale and evidence base. Curr. Opin. Infect. Dis. 2020, 33, 501-510. [CrossRef] [PubMed]

43. Bloos, F.; Rüddel, H.; Thomas-Rüddel, D.; Schwarzkopf, D.; Pausch, C.; Harbarth, S.; Schreiber, T.; Gründling, M.; Marshall, J.; Simon, P.; et al. Effect of a multifaceted educational intervention for anti-infectious measures on sepsis mortality: A cluster ran-domized trial. Intensive Care Med. 2017, 43, 1602-1612. [CrossRef]

44. Bloos, F.; Thomas-Rüddel, D.; Rüddel, H.; Engel, C.; Schwarzkopf, D.; Marshall, J.C.; Harbarth, S.; Simon, P.; Riessen, R.; Keh, D.; et al. Impact of compliance with infection management guidelines on outcome in patients with severe sepsis: A prospective observational multi-center study. Crit. Care 2014, 18, R42. [CrossRef]

45. Reignier, J.; Mercier, E.; La Gouge, A.; Boulain, T.; Desachy, A.; Bellec, F.; Clavel, M.; Frat, J.-P.; Plantefeve, G.; Quenot, J.-P.; et al. Effect of not monitoring residual gastric volume on risk of ventilator-associated pneumonia in adults receiving mechanical ventilation and early enteral feeding: A randomized controlled trial. JAMA 2013, 309, 249-256. [CrossRef] [PubMed]

46. Blot, S.I.; Poelaert, J.; Kollef, M. How to avoid microaspiration? A key element for the prevention of ventilator-associated pneumonia in intubated ICU patients. BMC Infect. Dis. 2014, 14, 1-6. [CrossRef]

47. Sager, R.; Kutz, A.; Mueller, B. Procalcitonin-guided diagnosis and antibiotic stewardship revisited. BMC Med. 2017, 15, 1-11. [CrossRef] [PubMed]

48. He, Y.; Wen, Q.; Yao, F.; Xu, D.; Huang, Y.; Wang, J. Gut-lung axis: The microbial contributions and clinical implications. Crit. Rev. Microbiol. 2017, 43, 81-95. [CrossRef]

49. Roberts, J.A.; Joynt, G.M.; Lee, A.; Choi, G.; Bellomo, R.; Kanji, S.; Mudaliar, M.Y.; Peake, S.L.; Stephens, D.; Taccone, F.S.; et al. The effect of renal replacement therapy and antibiotic dose on antibiotic concentrations in critically ill patients: Data from the multinational SMARRT Study. Clin. Infect. Dis. 2020, 72, 1369-1378. [CrossRef]

50. Beumier, M.; Casu, G.S.; Hites, M.; Wolff, F.; Cotton, F.; Vincent, J.L.; Jacobs, F.; Taccone, F.S. Elevated beta-lactam concentrations are associated with neurological deterioration in ICU septic patients. Minerva Anestesiol. 2015, 81, 497-506.

51. Imani, S.; Buscher, H.; Marriott, D.; Gentili, S.; Sandaradura, I. Too much of a good thing: A retrospective study of $\beta$-lactam concentration-toxicity relationships. J. Antimicrob. Chemother. 2017, 72, 2891-2897. [CrossRef]

52. Beumier, M.; Legros, B.; Wolff, F.; Cotton, F.; Jacobs, F.; Vincent, J.L.; Taccone, F.S. 933: Beta-lactams overdosing is associated with electroencephalographic abnormalities during sepsis. Crit. Care Med. 2013, 41, A234. [CrossRef]

53. Chow, K.M.; Szeto, C.C.; Hui, A.C.-F.; Wong, T.Y.-H.; Li, P.K.-T. Retrospective review of neurotoxicity induced by cefepime and ceftazidime. Pharmacother. J. Hum. Pharmacol. Drug Ther. 2003, 23, 369-373. [CrossRef] [PubMed]

54. Hagel, S.; on behalf of the TARGET Study Group; Fiedler, S.; Hohn, A.; Brinkmann, A.; Frey, O.R.; Hoyer, H.; Schlattmann, P.; Kiehntopf, M.; Roberts, J.A.; et al. Therapeutic drug monitoring-based dose optimisation of piperacillin/tazobactam to improve outcome in patients with sepsis (TARGET): A prospective, multi-centre, randomised controlled trial. Trials 2019, 20, 330. [CrossRef] [PubMed] 